\title{
O professor e sua responsabilidade na sociedade contemporânea
}

\author{
Ingrid Lilian Fuhr ${ }^{(\mathbb{D})}$ * \\ Centro Universitário de Brasília, Brasília, DF, Brasil
}

\begin{abstract}
Resumo
A sociedade contemporânea pode ser caracterizada por cinco aspectos que constituem as pontas de um pentagrama. Vivemos em uma sociedade escolarizada, em que a escola ocupa o lugar central da organização social; cientificista, dado que todo conhecimento presente no cotidiano tem reconhecimento social se legitimado pela ciência; mercadológica, uma vez que a lógica econômica rege as vidas das pessoas; judicializada, no momento em que as pessoas optam pelas vias juridicas para solucionar seus problemas pessoais, negando a possibilidade do diálogo; e medicalizada, em que os problemas sociais são compreendidos à luz da ciência médica como patológicos. O presente texto visa examinar como os cinco aspectos que constituem o pentagrama da sociedade contemporânea estão presentes no oficio docente e em que medida o professor abdica de sua responsabilidade social. Procura-se demonstrar que, no decorrer das últimas décadas, ocorreu a precarização do magistério, sua desqualificação na formação e no exercício profissional. Cada vez mais, os professores atuam como cumpridores de um programa educacional desvinculado de sua realidade de sala de aula.
\end{abstract}

Palavras-chave: professor; responsabilidade social; sociedade contemporânea.

\section{The teacher and his responsibility in contemporary society}

\begin{abstract}
Contemporary society can be characterized by five aspects that constitute the ends of a pentagram. We live in a schooled society, where school occupies the central place of social organization; scientist, since all knowledge present in everyday life has social recognition if legitimated by science; market, since economic logic rules people's lives; judicialized, when people choose the legal ways to solve their personal problems, denying the possibility of dialogue; and medicalized, in which social problems are understood in the light of medical science as pathological. This paper aims to examine how the five aspects that constitute the pentagram of contemporary society are present in the teaching profession and to what extent the teacher abdicates his social responsibility. It is aimed to demonstrate that in the last decades teaching was disqualified in its professional exercise. Increasingly, teachers act as compliant with an educational program that is detached from their classroom reality.
\end{abstract}

Keywords: teacher; social responsability; contemporary society.

A sociedade contemporânea brasileira é escolarizada, cientificista, mercadológica, medicalizada e judicializada. Esses cinco aspectos interligam-se intrinsecamente como uma teia tecida por pressupostos ideológicos que desenham um pentagrama. $\mathrm{O}$ texto visa examinar como esses aspectos que constituem as pontas de um pentagrama estão presentes no ofício docente e em que medida o professor abdica de sua responsabilidade social. Para tal, é necessário primeiramente explicitar os cinco aspectos que caracterizam a sociedade atual brasileira para posterior exame de como se interligam e constituem o exercício docente.

Ao considerar que vivemos numa sociedade escolarizada, admitimos indubitavelmente que a escola é um dos pilares estruturantes da organização social. A escola pós revolução industrial até os dias de hoje, em essência, pouco sofreu alteração. Ela continua imbuída de formar a mão de obra qualificada e de adequar os indivíduos às exigências da ideologia vigente, materializada por meio de programas governamentais à luz da lógica econômica. Promete preparar a criança e o jovem para a vida e formá-los cidadãos produtivos, adaptados aos padrões sociais, tendo como meta a aquisição de certificados como garantia de atender às exigências mercadológicas. $\mathrm{O}$ processo de escolarização, na sociedade contemporânea, assume

\footnotetext{
^Endereço para correspondência: Centro Universitário de Brasília - SEPN 707/907, Campus Universitário, Asa Norte, Brasília, DF. CEP: 70790-075. E-mail: ingridlfra@gmail.com

Os dados completos da autora encontram-se ao final do artigo.
}

papel de principal condição para o alcance de um futuro promissor e de uma vida digna. Sob o jugo da lei, as pessoas são obrigadas a cumprir anos de escolarização, em que os conhecimentos científicos sofrem transposição didática, sendo fragmentados em conteúdos distribuídos em anos de estudo (ILLICH, 1973).

A escola apresenta artifícios ordenadores para sua organização e controle, que devem ser apreendidos por todos, no mesmo tempo, espaço e currículo. A temporalidade escolar compreende o tempo prescrito e uniforme à sua administração, aos professores e aos estudantes. Caracteriza-se por estabelecer um ritmo próprio, síncrono, em que os estudantes devem aprender os mesmos conteúdos ensinados pelo professor ao mesmo tempo. A ordenação do espaço escolar visa ao controle de estudantes e professores; as salas de aula têm suas carteiras dispostas em fileiras ou em círculo, com suas portas com janelas para se observar o que acontece durante as aulas e o pátio interno em que as crianças ficam durante o recreio sob a vigia de educadores. Já o currículo estrutura o conhecimento científico em conteúdos estratificados, que devem ser ensinados e aprendidos por todos os estudantes do mesmo modo, ao mesmo tempo, e avaliados por meio de provas que requerem respostas padronizadas, além da pontualidade, da frequência obrigatória, da autosubmissão e do silêncio (BOTO, 2003). 
Com o discurso da oportunidade para todos, cria-se a ilusão da inclusão, nivelando todos os estudantes por um determinado padrão. A engrenagem da escolarização promove a mesmidade, ou seja, pensar do mesmo modo, comportar-se conforme estipulado; tudo é organizado de modo a domesticar crianças e jovens, que devem se adequar e atender às exigências estabelecidas pelo padrão almejado. Os que sobrevivem são aceitos pela comunidade escolar. Já os que, por alguma razão, não correspondem ao esperado são autoexcluídos ou encaminhados para diagnóstico, como condição para continuarem na escola. A institucionalização do aprender leva as pessoas a acreditarem que, para estudar e aprender algum conhecimento científico, necessitam estar matriculadas em uma instituição escolar e ter o aval de anos de escolarização validados por meio de um certificado. As pessoas são levadas a pensar que quanto maior o tempo de escolarização melhor será a formação de cidadãos (FREITAS, 2002). Em síntese, a educação reduziu-se à escolarização, à aprendizagem.

Sob a perspectiva cientificista, uma sociedade caracteriza-se pela crença de que a ciência é eticamente neutra, isenta de qualquer influência ideológica, e de que tudo pode ser explicado e comprovado empiricamente. Para ser reconhecido socialmente, o conhecimento necessita da chancela da ciência. Esta visão é perpetuada no ideário social, a ponto de as pessoas se submeterem às informações e às descobertas científicas, acreditando que a ciência responderá aos conflitos e dramas presentes na vida cotidiana. Essa atitude de submissão à ciência lhe confere um poder de autoridade e controle sobre as vidas das pessoas (FUHR, 2018).

Contudo, há estreita relação entre ciência, mercado e política de Estado. A ciência, orientada pela ideologia vigente e atendendo às exigências de mercado, fornece dados estatísticos e subsídios para o fomento de políticas de Estado, que se materializam em programas de governo e em instruções às instituições sociais. É comum encontrar nas mídias e em textos oficiais termos científicos com o propósito de validar informações e ideias do senso comum, tornando-as inquestionáveis. Afirma-se que a informação é comprovada cientificamente, e as pessoas não questionam (FUHR, 2018).

A ideia de que a ciência moderna possui o poder de esclarecer a realidade e de ordenar o mundo produz verdades que requerem o cumprimento absoluto de regras instituídas. A racionalidade científica modela o mundo e institui a razão médica. Esta, ao adquirir o poder e a tarefa de legislar sobre a vida das pessoas, estabelece as condições para a subserviência às normas e regras instituídas por ela. A racionalidade científica designa a normalização das pessoas e das relações sociais a serem cumpridas em conformidade com a visão de homem contemporâneo. Para tal, a medicina elabora conceitos de normalidade e patologia, equilíbrio e desvio, harmonia e perturbação. As condutas a serem seguidas pelas pessoas são determinadas por exigência de instituições sociais para garantir a harmonia social e a normalidade. A ciência médica, em estreito diálogo com o mercado e com a ideologia de Estado, exerce domínio sobre as pessoas por meio do consumo de tratamentos, terapias e produtos industrializados, sob a ótica do controle social exclusivo e a satisfação de necessidades prementes. Todos, de uma forma ou de outra, atendem ao que é normatizado pelos padrões sociais vigentes. As pessoas são submetidas a princípios externos e estranhos à sua razão; todavia submetem-se, gerando um processo de adoecimento social, denominado por Illich (1975) de medicalização.

O processo de medicalização, outro aspecto da sociedade contemporânea, limita a autonomia das pessoas; elas sentem-se incapazes de decidir sobre suas vidas e fazer o que podem por si mesmas e para os outros sem a aprovação do médico ou de um profissional da saúde. Os padrões normatizados sustentam práticas de manipulação ideológica que as levam a crer em sua incapacidade de gerir suas vidas autonomamente. Os problemas sociais são compreendidos como distúrbios e doenças, como algo que deva ser curado por fugir às normas estabelecidas. Almejam-se corpos sadios, belos, perfeitos e produtivos. A preocupação obstinada com a saúde, com os modelos de homem e mulher saudáveis, condiciona rotinas, conforme as últimas descobertas e pesquisas científicas. Trata-se de discurso genérico homogeneizador, que desconsidera a diversidade de modos de existir e de viver em sociedade (ILLICH, 1975).

A norma social tutela a vida das pessoas, propaga o equilíbrio emocional, a tranquilidade, a solicitude, a sociabilidade, a resignação diante das injustiças e a passividade diante dos horrores do mundo. Profissionais especializados categorizam as pessoas que apresentam diferença ou disfunção em relação ao padrão estipulado. As rotuladas como anormais e estranhas são encaminhadas a tratamentos especiais para sua anomalia, com vistas à adequação social, exercendo um duplo papel na sociedade medicalizada, o de provocar a necessidade de formação de novos profissionais especializados para seu atendimento e o de sustentar a lógica da ordem social imposta. A ciência médica enraíza-se em todos os espaços sociais e, com um modo empresarial de se autogerir, conduz as pessoas a consumirem tratamentos e pacotes de saúde estética para corrigir qualquer defeito físico, ampliar a longevidade e conquistar o padrão valorizado socialmente, com a promessa do estado pleno de felicidade. Tornam-se eternos clientes e incessantemente buscam por meio do diagnóstico médico a solução de seus problemas.

A medicina enraizou-se em diferentes espaços sociais e há um em especial, a escola, que perpetua a medicalização com suas práticas patologizantes. Nos discursos dos profissionais da saúde e da educação percebe-se a coesão ideológica da medicalização, em que a criança, ao não atender às expectativas dos professores e dos pais, bem como por apresentar comportamentos considerados inadequados, conforme as normas, é vista como alguém que necessita de tratamento e incapaz de acompanhar o ritmo estabelecido pela dinâmica pedagógica em sala de aula. É requerido dos pais o diagnóstico médico e psicológico para que ela possa dar continuidade à sua formação es- 
colar. O diagnóstico se torna uma ferramenta de controle social. O modo empresarial de exercer a medicina move o mercado (ILLICH,1975).

Outra forma de caracterizar a sociedade contemporânea é pelo aspecto mercadológico. Ela é regida por interesses econômicos que privilegiam o lucro em detrimento das necessidades sociais da população. $\mathrm{O}$ pensamento econômico vigente é o neoliberalismo, oriundo do liberalismo econômico clássico que tinha como princípio organizador da sociedade a defesa de um mercado autorregulável que sofreu alterações no decorrer das décadas do século passado (POLANYI, 2000). O neoliberalismo compreende um processo de construção social hegemônico por meio de reformas no plano econômico, político, jurídico e educacional, com vistas a superar a crise capitalista que começou ao final dos anos de 1960 e se manifestou claramente nos anos de 1970. No Brasil, o neoliberalismo ganhou ampla aceitação nas décadas de 80 e 90, com o objetivo de estimular o desenvolvimento econômico sem a interferência do Estado na economia. O neoliberalismo compreende um conjunto de ideias políticas e econômicas que defende a liberdade do mercado, com vistas a garantir o crescimento econômico e o desenvolvimento social de um país. Para tal, defende o ajuste fiscal, eliminando o déficit público, a redução da máquina estatal, a privatização, a abertura comercial com a redução de alíquotas de importação, de modo a ampliar as exportações e impulsionar a globalização da economia, o fim das restrições à entrada de capital estrangeiro, a autorização para que instituições financeiras estrangeiras possam atuar em igualdade de condições com as do país, a fiscalização dos gastos públicos e o investimento em infraestrutura básica (FILGUEIRAS, 2006). Como afirma Gentili (1996), a imposição de um novo discurso que explica a crise econômica e social e apresenta respostas, estratégias e verdades defendidas como solução promoveu certo êxito cultural, ao apontar-se como única saída possível. Trata-se de uma reforma ideológica da sociedade com a difusão de um novo senso comum estruturado coerentemente com os pressupostos neoliberais.

O presente texto se centra nas repercussões da retórica neoliberal no campo educacional. Sob essa perspectiva, os sistemas de ensino enfrentam uma crise profunda de eficiência e de eficácia decorrente da improdutividade das práticas pedagógicas e da gestão administrativa na maioria das instituições de ensino público. Assim, os mecanismos de exclusão e de discriminação educacional são resultantes da ineficácia da escola e da incompetência dos profissionais que nela trabalham. Ou seja, os sistemas de ensino público não enfrentam uma crise de democratização, mas gerencial. Diante desse cenário, reformas pedagógicas e de gestão são propostas à luz de políticas neoliberais, por meio de mecanismos que regulem a eficiência, a produtividade e a qualidade de serviços oferecidos. Para tal, é necessária uma reestruturação dos sistemas de ensino, com mudanças substantivas nas práticas pedagógicas e nas estratégias de gestão, com a implementação de uma reforma curricular e de um novo perfil de professor. Criam-se sistemas de avaliação com o intuito de diagnosticar problemas de rendimento dos estudantes e da produtividade das escolas, de desenvolver parâmetros e conteúdos básicos de um currículo nacional e de aprimorar a formação de professores sob a ótica neoliberal. Todavia, os sistemas de avaliação criaram ranques de escolas, que levaram as que obtiveram melhor pontuação a receberem mais recursos financeiros. A competição promovida pelos sistemas de avaliação com base em critérios meritocráticos estabelece condições para uma mudança institucional voltada para o mercado educacional. O Estado neoliberal estabelece mecanismo de verticalização antidemocrático por meio de avaliação dos sistemas, retirando a autonomia pedagógica das instituições e principalmente dos professores. Para os neoliberais a crise social se explica pela ineficiência do Estado em gerenciar políticas públicas, por não atuar como uma empresa. O desafio que se apresenta para a política neoliberal é transferir a educação da esfera política para a esfera do mercado, reduzindo-a à condição de propriedade. Assim, a noção de cidadania calca-se na valorização do indivíduo enquanto proprietário que busca adquirir mercadorias, sendo a educação uma delas. A educação escolarizada se constitui de produtos como o conhecimento, o estudante, o professor e o certificado, tornando-se mercadoria de grande valor social. O modelo de homem neoliberal é o cidadão privatizado, um consumidor (GENTILI, 1996).

Por fim, o último aspecto do pentagrama estrutural da sociedade contemporânea brasileira é a judicialização. Ela está calcada em uma sociedade de caráter punitivo, expandindo-se a lógica de tribunais para a resolução de problemas cotidianos. A judicialização da vida ocorre quando o Poder Judiciário assume lugar de destaque em relação ao Poder Legislativo e Executivo, com crescente relevância social. Ocorre na medida em que as relações sociais, diante de conflitos e dramas que permeiam a vida cotidiana, são terceirizadas. Nega-se a possibilidade de diálogo direto de modo a conciliar conflitos que surgem nas relações humanas no dia a dia. As pessoas, ao recorrerem a juízes, promotores, advogados e aos conselhos tutelares para mediar, punir, regrar os efeitos de desacordos que surgem na vida cotidiana, demandam a intervenção do Poder Judiciário. Desse modo, o processo de judicialização exerce o papel de mediador do viver.

Nesse cenário, uma das encomendas mais reivindicadas é a criação de mais e mais leis, uma proliferação legalista e punitiva. Porém, mais que isso, a máquina jurídica se multiplica nas ações cotidianas. O Poder Judiciário parece converter-se em uma espécie de arena única, para a qual convergem os pedidos marcados por dores e dramas variados, os quais são reduzidos em sua complexidade em nome da vingança reativa do Direito Positivo Penal e Retributivo (SILVA et al., 2015, p. 225).

Como afirmam Silva et al. (2015), a judicialização aparece no cenário social nas últimas décadas do século XX e nos primeiros anos do século XXI, no contexto da crise do Estado de Bem-Estar, na desregulamentação da economia neoliberal e na globalização da economia. $\mathrm{O}$ processo de judicialização promove a jurisdicionalização 
(poder-dever de realização de justiça estatal, por órgãos especializados do Estado) abrangendo a regulação da sociabilidade das relações sociais, fato este a que a intervenção do Estado não se aplicava.

Tudo e todos passaram a ser passíveis a uma resposta jurídica e de uma explicação qualquer, a partir dos códigos do Direito, que possam porventura justificar a si e as suas ações. A jurisdicionalização se dá em defesa de costumes e na busca por verdades, que é um dos componentes fundamentais da moral. Essas verdades podem se materializar nos códigos jurídicos, por meio das leis e dos aparatos que as sustentam [...], produzindo modos de vida moralizantes, revestidos pela doutrina do juízo. [...] para o exercício de uma intervenção na vida da população, inclusive em seu âmbito privado. Ou seja, reclamar por justiça parece simplesmente reduzir qualquer luta ao denuncismo e ao pedido de endurecimento penal, em mais e mais aberturas de processos por danos morais e a litígios infindáveis por tensões familiares, de trabalho, de vizinhos e entre amigos. [...] E, aliada a essa lógica, encontra-se a da jurisdicionalização, que tem como funcionamento a produção massiva de discursos e práticas punitivo-criminalizantes, que no contemporâneo vão se espalhando no tecido social (SILVA et al., 2015, p. 228-230).

Relações sociais forjadas em cultura punitiva defendem o castigo e a vingança como forma de justiça social, em que a vitimização promove a criminalização de comportamentos e a judicialização se materializa de modo punitivo em toda a sociedade. Numa sociedade disciplinar, a vigilância produz docilidade, e a ideologia neoliberal, com seus mecanismos de controle social, cria uma diversidade de modos de vigilância dentro das instituições. "Tornar cada cidadão um vigilante do direito tem produzido relações de ameaça sustentadas no julgamento sistemático entre as pessoas. Todos nos tornamos juízes; todos nós julgamos, punimos e condenamos, ou pedimos a pena; acreditamos na pena e modulamos as punições" (SILVA et al., 2015, p. 232, 233). Desse modo, são fortalecidos os mecanismos de controle social por meio de um Estado representativo e policial que, baseado em verdades absolutas prescritas em códigos normalizadores, materializa estratégias de dominação.

Outrossim, a escola é uma das instituições sociais que possibilitam tudo ver e vigiar permanentemente. Com o intuito de detectar perigos para estudantes e professores, a comunidade escolar fortalece mecanismos de controle justificados pela insegurança, requisitando a presença policial. O processo de judicialização/policial serve como saída para situações de conflito e de violência no ambiente escolar. A racionalidade da segurança sustenta a judicialização, a criminalização e a normalização da vida. Percebe-se a ausência de diálogo e de debate, dentro do espaço escolar, sobre os problemas sociais e conflitos do dia a dia. A comunidade escolar abdicou de exercer sua autoridade no processo educativo, terceirizando sua função. A prática é silenciar e domesticar, reprimir qualquer perturbação.

Assim, os cinco aspectos que caracterizam a sociedade atual brasileira interligam-se intrinsecamente e se retroalimentam sob a ideologia neoliberal. Diante do cenário exposto e tomando por base que um professor é um profissional que deva ser comprometido eticamente com a formação educacional de seus estudantes, cabe indagar em que medida ele abdica de sua responsabilidade social.

A visão economicista de educação perdura e está mais veemente na atualidade. Como afirma Freitas (2018), um dos objetivos do neoliberalismo é obter a gestão do processo educativo de modo a inculcar a hegemonia de ideias neoliberais nos estudantes. Cria-se uma relação direta entre boa educação e elevação das notas da escola, por meio de avaliações em larga escala orientadas pelas agências internacionais, como referência para as avaliações de políticas educacionais em âmbito internacional. Confunde-se boa educação com boa aprendizagem, compreendida como um conjunto de habilidades e competências a serem desenvolvidas pelos estudantes, conforme exigências do mercado. Paulatinamente, ocorreu um movimento de aceitação por parte dos professores das reformas neoliberais, muitos se encantaram com as novas diretrizes que a política de Estado de educação deseja implantar. Apresentou-se à comunidade docente e equipe técnica das secretarias de educação o despertar de uma nova era de progresso, ao passo que as novas medidas fossem implementadas sob a orientação do Banco Mundial e do Banco Internacional para Reconstrução e Desenvolvimento (BIRD). Com a anuência do governo federal e a receptividade dos técnicos do Ministério da Educação e das secretarias estaduais e municipais de educação, desenvolveu-se a ingerência dos organismos financeiros internacionais na fiscalização e gestão dos programas institucionais implementados em todos os sistemas de ensino.

A visão de mercado penetrou no espaço escolar. Sob a lógica empresarial, medidas foram tomadas para o melhor funcionamento da instituição e da produtividade do professor. A retórica neoliberal apresenta soluções simples, a priori, para problemas enfrentados pelos professores em seu ofício diário, o que os agrada, sem uma discussão aprofundada dos fins da educação escolar. Os documentos institucionais respaldados pela ciência apresentaram reformas curriculares e velhas ideias travestidas de novas propostas pedagógicas no decorrer das últimas décadas. $\mathrm{O}$ enfoque central é a aprendizagem dos estudantes, que, pelas avaliações realizadas, apontam baixo rendimento escolar. Assim, as avaliações assumem proeminência na escolarização, e há constantemente uma pressão para atingir patamares internacionais.

Medidas verticalizadas pela política de Estado foram tomadas, de modo autoritário, e a reflexão sobre o trabalho pedagógico foi gradativamente diluindo-se com os procedimentos burocráticos a serem cumpridos. Sem um exame detalhado da complexidade que caracteriza o país diante da diversidade cultural e de contextos econômi$\cos$ diferenciados, estabeleceu-se um padrão universal de ensino por todo o território brasileiro. As resistências de muitos professores e técnicos de educação foram gradativamente se desvanecendo. Todavia, muitos ainda resistem em defesa da escola pública e em sua responsabilidade social de educadores. Além da visão mercadológica da educação, no decorrer das últimas décadas aconteceu a precarização do magistério, sua desqualifi- 
cação na formação e no exercício profissional. Cada vez mais, os professores atuam como cumpridores de um programa educacional desvinculado de sua realidade de sala de aula (FREITAS, 2018).

Cabe salientar que os professores compactuam com o processo de medicalização ao rotularem crianças e jovens que não se adéquam a critérios e padrões estabelecidos. Ao encaminharem uma criança para avaliação médica e psicológica, abdicam de sua responsabilidade de ensinar, aguardando o diagnóstico de suas crianças, culpabilizando-as por não seguirem o ritmo estipulado por eles. Qualquer comportamento inadequado da criança é considerado patológico. Com o discurso da inclusão, crianças consideradas e diagnosticadas como deficientes são deixadas à margem do processo de escolarização. É comum ouvir de professores que são crianças que não aprendem, estão na sala de aula para socializar. O professor sente-se respaldado em sua desresponsabilização pelo diagnóstico.

O espaço escolar também está judicializado. Além de muitos professores apoiarem o policiamento dentro da escola, como forma de disciplinar os estudantes, terceirizam sua responsabilidade de educador ao encaminharem crianças para avaliação médica e psicológica. Recentemente acompanhei o caso de uma criança de quatro anos, em que foi exigido da mãe um diagnóstico médico. Após o diagnóstico de Transtorno de Déficit de Atenção e Hiperatividade/TDAH, a mãe se negou a ministrar ritalina a sua filha. A professora ameaçou-a ao dizer que chamaria o Conselho Tutelar para tratar do caso e que ela corria o risco de perder a guarda da filha. A mãe, amedrontada, passou a ministrar a ritalina. Esse é apenas um de tantos casos que ocorrem na escola à luz da judicialização.

As novas medidas neoliberais consistem na eficiência do sistema educacional sob a lógica empresarial em um livre mercado, sem a intervenção do Estado.

O neoliberalismo atual traz consigo o autoritarismo social. Esta combinação está presente na sociedade contemporânea e é retroalimentada por todos os cidadãos, direta ou indiretamente. No caso específico da escola, o professor tem compromisso ético com seus estudantes e responsabilidade social que deveria ser reconquistada. Somos todos responsáveis eticamente pelos rumos que seguirá a sociedade atual brasileira diante do cenário caracterizado por um pentagrama, que degrada a vida humana.

\section{Informações sobre a autora:}

Ingrid Lilian Fuhr

(iD) https://orcid.org/0000-0003-2792-5778

(9) http://lattes.cnpq.br/1036916173431805

Possui mestrado e doutorado em Educação pela Universidade de Brasília/UNB, onde se graduou em Pedagogia. Atualmente é professora do Centro Universitário de Brasília (UniCEUB), lecionando nos cursos de graduação e pós-graduação. Desenvolve pesquisa sobre os seguintes temas: desenvolvimento humano, pensamento conceitual em atividades artesãs, conhecimento científico e conhecimento escolar, desenvolvimento atípico e deficiência, processo de escolarização e medicalização.

\section{Como citar este artigo:}

\section{ABNT}

FUHR, Ingrid Lilian. O professor e sua responsabilidade na sociedade contemporânea. Fractal: Revista de Psicologia, Niterói, v. 32, n. esp., p. 199-203, jun. 2020. https://doi.org/10.22409/19840292/v32 i-esp/38852

\section{APA}

Fuhr, I. L. (2020, Junho). O professor e sua responsabilidade na sociedade contemporânea. Fractal: Revista de Psicologia, 32(esp.), 199-203. doi: https://doi.org/10.22409/1984-0292/v32_i$\operatorname{esp} / 38852$

\section{Copyright:}

Copyright (C) 2020 Fuhr, I. L. Este é um artigo em acesso aberto distribuído nos termos da Licença Creative Commons Atribuição que permite o uso irrestrito, a distribuição e reprodução em qualquer meio desde que o artigo original seja devidamente citado.

Copyright (C) 2020 Fuhr, I. L. This is an Open Access article distributed under the terms of the Creative Commons Attribution License, which permits unrestricted use, distribution, and reproduction in any medium, provided the original article is properly cited.

\section{Referências}

BOTO, Carlota. A civilização escolar como projeto político e pedagógico da modernidade: cultura em classes, por escrito. Cadernos Cedes, Campinas, v. 23, n. 61, p. 378-397, dez. 2003. http://dx.doi.org/10.1590/S0101-32622003006100008

FILGUEIRAS, Luiz. O neoliberalismo no Brasil: estrutura, dinâmica e ajuste do modelo econômico. In: BASUALDO, Eduardo M.; ARCEO, Enrique (Org.). Neoliberalismo y sectores dominantes: tendencias globales y experiencias nacionales. Buenos Aires: CLACSO, 2006. p. 179-206. Colección Grupos de Trabajo.

FREITAS, Luiz Carlos de. A internalização da exclusão. Educação e Sociedade, Campinas, v. 23, n. 80, p. 299-325, sept. 2002. http://dx.doi.org/10.1590/S0101-73302002008000015

FREITAS, Luiz Carlos. A reforma empresarial da educação: nova direita, velhas ideias. São Paulo: Expressão Popular, 2018.

FUHR, Ingrid Lilian. Atividades cotidianas e o pensamento conceitual. Curitiba: CRV, 2018.

GENTILI, Pablo. Neoliberalismo e educação: manual do usuário. In: SILVA, Tomaz Tadeu da; GENTILI, Pablo (Org.). Escola $S$. A.: quem ganha e quem perde no mercado educacional do neoliberalismo. Brasília, DF: CNTE, 1996. p. 9-49.

ILLICH, Ivan. Sociedade sem escolas. Petrópolis: Paz e Terra, 1973.

ILLICH, Ivan. A expropriação da saúde: Nêmesis da medicina. Rio de Janeiro: Nova Fronteira, 1975.

POLANYI, Karl. A grande transformação: as origens de nossa época. Rio de Janeiro: Elsevier, 2000.

SILVA, Cristiane Freitas da et al. Reflexões a respeito dos processos de judicialização e criminalização no controle da contemporaneidade. Barßarói, Santa Cruz do Sul, n. 43, p. 223-241, jan./jun. 2015. http://dx.doi.org/10.17058/barbaroi. v0i0.4054 